\title{
Functional Analysis of Capsaicin Receptor (Vanilloid Receptor Subtype 1) Multimerization and Agonist Responsiveness Using a Dominant Negative Mutation
}

\author{
Eldo V. Kuzhikandathil, ${ }^{1}$ Haibin Wang, ${ }^{1}$ Tamas Szabo, ${ }^{2}$ Natasha Morozova, ${ }^{1}$ Peter M. Blumberg, ${ }^{2}$ and \\ Gerry S. Oxford 1 \\ 'Department of Cell and Molecular Physiology and the Neuroscience Center, University of North Carolina, Chapel Hill, \\ North Carolina 27599, and 2National Cancer Institute, Bethesda, Maryland 20892
}

The recently cloned vanilloid receptor subtype 1 (VR1) is a ligand-gated channel that is activated by capsaicin, protons, and heat. We have attempted to develop a dominant negative isoform by targeting several mutations of VR1 at highly conserved amino acids or at residues of potential functional importance and expressing the mutants in Chinese hamster ovary cells. Mutation of three highly conserved amino acid residues in the putative sixth transmembrane domain disrupts activation of the VR1 receptor by both capsaicin and resiniferatoxin. The vanilloid binding site in this mutant is intact, although the affinity for $\left[{ }^{3} \mathrm{H}\right]$ resiniferatoxin (RTX) is diminished by nearly 40 -fold. Interestingly, this mutant retains a significant but diminished response to protons, supporting the existence of multiple gat-

Responsiveness of primary afferent neurons to the vanilloid capsaicin has long served as the functional signature of a particular class of sensory neurons referred to as nociceptors (Szallasi and Blumberg, 1999). Despite abundant pharmacological data characterizing the capsaicin receptor, the molecular entity underlying the response remained unknown until the primary sequence for a capsaicin receptor was obtained by expression cloning (Caterina et al., 1997). Vanilloid receptor subtype 1 (VR1) is a ligand-gated ion channel that integrates multiple noxious stimuli, including capsaicin, protons, and heat (Caterina et al., 1997; Tominaga et al., 1998; Caterina and Julius, 2001). Two VR1 receptor homologs, a stretch-inhibitable channel (SIC) and vanilloid receptor-like protein 1 (VRL-1) have subsequently been cloned (Caterina et al., 1999; Suzuki et al., 1999). Previous studies have suggested the existence of multiple vanilloid receptors (Szallasi and Blumberg, 1999); however, pharmacological or molecular tools to distinguish the function of these individual receptor subtypes have been lacking. A recent study indicated that calcium responses and resiniferatoxin binding properties that have been attributed to different receptors can be recapitulated by expression of only rat VR1 (Szallasi et al., 1999), suggesting complex functional properties of the VR1 protein. Despite significant

Received July 10, 2001; revised Aug. 21, 2001; accepted Aug. 23, 2001.

This study was supported by National Institutes of Health Grants NS18788 and NS39420 to G.S.O. and by a Howard Hughes Pilot Studies grant to E.V.K. We thank Rakhshi Khan and Suman Vidyarthyi for technical assistance in generating the VR1 mutations and cell lines. In addition, we thank Doug Krafte and David Printzenhoff (ICAgen, Inc.) for help with the FLIPR experiments.

Correspondence should be addressed to Dr. Gerry S. Oxford, Department of Cell and Molecular Physiology, University of North Carolina, Box 7545, 452 Medical Science Research Building, Chapel Hill, NC 27599. E-mail: gsox@med.unc.edu. Copyright (C) 2001 Society for Neuroscience 0270-6474/01/218697-10\$15.00/0 ing mechanisms for different stimuli. The mutant appears to function by interfering with the gating induced by vanilloids rather than the expression level or permeability of the receptor. In addition, this mutant was found to function as a strong dominant negative mutation when coexpressed with wild-type VR1, providing functional evidence that the VR1 receptor forms a multimeric complex. Analysis of both current density and $\left[{ }^{3} \mathrm{H}\right] \mathrm{RTX}$ affinity in cells cotransfected with different ratios of wild-type and mutant VR1 is consistent with tetrameric stoichiometry for the native capsaicin receptor.

Key words: capsaicin; dominant negative; VR1; pain; resiniferatoxin; mutation; $\mathrm{CHO}$ cell

functional analysis of the responses of heterologously expressed VR1 (Caterina et al., 1997; Tominaga et al., 1998), the structural features of VR1 receptor subtypes that confer responsiveness to pain-producing stimuli are not clear. Specifically, amino acid residues involved in ligand binding, ion permeability, gating, desensitization, and other receptor properties have remained mostly unidentified. The only reports of functionally relevant mutations involve glutamine residues near the putative pore domain that alter sensitization of capsaicin responses by protons and proton activation of VR1 (Jordt et al., 2000; Welch et al., 2000). In addition, it has not been experimentally demonstrated that the functional capsaicin receptor constitutes a multimeric complex, by analogy with many other ion channels, as is widely speculated.

In an effort to assess whether the receptor is a multimeric protein, we sought to find mutations that would render the receptor nonfunctional and possibly serve as dominant negative components when coexpressed with wild-type VR1. Here we report the effects of mutations in selected amino acids in VR1, including residues in the sixth transmembrane domain, implicated by their high degree of conservation between VR1 and related receptors and channels. Mutation of residues in the sixth transmembrane domain completely disrupts the ability of capsaicin and resiniferatoxin to activate $\mathrm{VR} 1$, yet this mutant retains the ability to respond to protons. In addition, we have found that this nonfunctional mutant can be an effective dominant negative subunit to abrogate wild-type VR1 receptors, providing the first functional evidence for the multimeric nature of the VR1 receptor-channel complex. Moreover we have used this feature to assess the functional stoichiometry of the wild-type capsaicin receptor. These mutants provide new opportunities to examine the heteromultim- 
erization properties of VR1-like receptors as well as the functional topology of the receptor.

These results have been published previously in abstract form (Sharkey et al., 1999; Oxford et al., 2000).

\section{MATERIALS AND METHODS}

Cell culture and transfection. Chinese hamster ovary (CHO) cells were grown in Ham's F-12 medium with $10 \%$ FCS and $100 \mathrm{U} / \mathrm{ml}$ penicillin and streptomycin. Cells were plated on glass coverslips coated with $40 \mu \mathrm{g} / \mathrm{ml}$ poly-L-lysine and transiently transfected with an expression plasmid encoding the VR1 receptor (kindly provided by Dr. David Julius, University of California, San Francisco, CA) and a reporter plasmid encoding enhanced green fluorescent protein (EGFP; Clontech, Palo Alto, CA) using the LipofectAMINE reagent according to instructions from the manufacturer (Life Technologies, Inc., Gaithersburg, NY). Expression efficiency of $15-40 \%$, assessed by EGFP fluorescence and inward currents, was routinely achieved. CHO cells stably expressing the rat VR1 receptor were generated by clonal selection after LipofectAMINE (Life Technologies)-mediated transfection, and stable transfectants were maintained in $500 \mu \mathrm{g} / \mathrm{ml}$ geneticin (Life Technologies).

Site-directed mutagenesis. The plasmid encoding the rat VR1 receptor was denatured and annealed to a selection primer (which converted a unique $S c a$ I restriction enzyme site in rat VR1 plasmid to $S t u \mathrm{I}$ ) as well as the mutagenic primers. The following mutagenic primers were used to generate the mutant VR1 receptors: 5' -gagtccacactacacaagtgc-3' (P613L mutant), 5' -ggtctgccggcaagctaggtaactc-3' (CP621GL mutant), 5' -gtccacaccaaccaagtgccgg-3' (H614T mutant), and 5'-cettctgctcttcgcgeccattgc-3' (NML676FAP mutant). Second-strand DNA synthesis from annealed primers was performed using T4 DNA polymerase (New England Biolabs, Beverly, MA). The gaps in the modified plasmids were sealed using T4 DNA ligase (New England Biolabs). The $S c a$ I restriction enzyme was used to linearize unmodified plasmids but not to affect the modified plasmids (which had incorporated the selection and mutagenic primers). This step reduced the subsequent transformation efficiency of linear unmodified plasmids compared with the circular modified plasmids. The mixture of linear unmodified and circular modified plasmids was then transformed into Escherichia coli BMH 71-18 mutS (Clontech). This strain, being DNA mismatch repair-deficient, allows the propagation of modified plasmids containing the selection and mutagenic primer. Plasmid DNA isolated from transformed $E$. coli $\mathrm{BMH}$ 71-18 mutS colonies was pooled and redigested with $S c a$ I to linearize unmodified plasmids and to further enrich the population of circular modified plasmids. This mixture of plasmids was then transformed into E. coli DH5 $\alpha$ (Life Technologies). Plasmid DNA was isolated from individual colonies and characterized by both restriction enzyme mapping and DNA sequencing. Clones that contained the desired substitutions in the rat VR1 gene were identified and subjected to additional DNA sequencing to confirm that this was the only change incorporated.

Drugs and solutions. A $10 \mathrm{~mm}$ capsaicin (Research Biochemicals, Natick, MA) stock was prepared in ethanol and used at a final concentration of $1 \mu \mathrm{M}$ except where indicated. A $0.5 \mathrm{~mm}$ resiniferatoxin (Sigma, St. Louis, MO) stock was prepared in ethanol and used at a final concentration of $50 \mathrm{~nm}$. A $10 \mathrm{~mm}$ capsazepine (Research Biochemicals) stock was made in ethanol and used at a final concentration of $10 \mu \mathrm{M}$. All control solutions contained equivalent concentrations of the ethanol solvent. The drug solutions were applied to the cells via gravity from an array of $3 \mu$ l glass capillaries (Drummond Microcaps, Broomall, PA) or small quartz tubes (Polymicro Technologies, Phoenix, AZ).

Electrophysiology. Agonist-activated currents were measured using patch electrodes in the whole-cell configuration with either an Axopatch 1B or Axopatch 200 amplifier (Axon Instruments, Foster City, CA). Data were collected and analyzed using Clampex7 software (Axon Instruments), and graphs and statistical tests were performed in SigmaPlot (SPSS, Chicago, IL). Patch pipettes were constructed from N51A glass (Drummond), coated with dental wax (Sticky Wax; Kerr, Romulus, MI), and polished on a homemade microforge at $600 \times$ magnification. All experiments were performed at room temperature $\left(21-23^{\circ} \mathrm{C}\right)$. The cells were voltage-clamped at a holding potential of $-60 \mathrm{mV}$, and the current responses to ligands were normalized to the cell capacitance (picoamperes per picofarads), to account for variation in cell size. The standard external solution (SES) used in electrophysiology experiments contained (in $\mathrm{mM}$ ): $145 \mathrm{NaCl}, 5 \mathrm{KCl}, 2 \mathrm{CaCl}_{2}, 1 \mathrm{MgCl}_{2}, 10 \mathrm{HEPES}$, and 10 glucose. The calcium-free external solution $(0 \mathrm{Ca}$-ES $)$ was identical with the exception of no added calcium, $4 \mathrm{~mm} \mathrm{MgCl}$, and $1 \mathrm{~mm}$ EGTA to chelate ambient calcium. The internal solution in the patch electrode contained (in $\mathrm{mM}$ ): 130 potassium aspartate, $20 \mathrm{KCl}, 1$ EGTA, $1 \mathrm{MgCl}_{2}, 10$ HEPES, and 10 glucose. All solutions were adjusted to a $\mathrm{pH}$ of 7.4 and osmolarity of $\sim 300 \mathrm{mOsm}$. The $\mathrm{pH} 5.0$ solution was made by substituting Tris maleate for HEPES and $\mathrm{NaOH}$ titration in either SES or 0 Ca-ES.

Resiniferatoxin binding. $\left[{ }^{3} \mathrm{H}\right]$ Resiniferatoxin (RTX) $(47 \mathrm{Ci} / \mathrm{mmol})$ was obtained from DuPont NEN (Wilmington, DE). Nonradioactive RTX was purchased from LC Laboratories (Woburn, MA). Specific $\left[{ }^{3} \mathrm{H}\right] \mathrm{RTX}$ binding was determined in frozen cell pellets of either stably or transiently transfected $\mathrm{CHO}$ cells. Frozen cell pellets were resuspended in ice-cold $10 \mathrm{~mm}$ HEPES, pH 7.4, containing (in mM): $5 \mathrm{KCl}, 5.8 \mathrm{NaCl}, 2$ $\mathrm{MgCl}_{2}, 0.75 \mathrm{CaCl}_{2}, 12$ D-glucose, and 137 sucrose (buffer A).

Incubations were performed in a MultiScreen-DV 96-well sterile plate (Millipore, Marlborough, MA). Graded concentrations of $\left[{ }^{3} \mathrm{H}\right] \mathrm{RTX}$ were incubated in a total volume of $300 \mu \mathrm{l}$ with $100 \mu \mathrm{l}$ of cell suspension ( $\sim 40-50 \mu \mathrm{g}$ of total protein) for $60 \mathrm{~min}$ at $37^{\circ} \mathrm{C}$ in buffer A supplemented with $0.25 \mathrm{mg} / \mathrm{ml}$ bovine serum albumin (type $\mathrm{V}$; Sigma). The bovine serum albumin was included to reduce nonspecific adsorption of RTX to surfaces (Szallasi et al., 1992). At the end of the incubation, the plate was chilled on ice, and $100 \mu \mathrm{g}$ of $\alpha 1$-acid glycoprotein (Sigma) in a $50 \mu \mathrm{l}$ volume was added to each well to reduce nonspecific binding. Bound and free $\left[{ }^{3} \mathrm{H}\right] \mathrm{RTX}$ were then separated by filtration using a MultiScreen vacuum manifold (Millipore). The supernatants were collected into a 96-well plate that had been placed underneath the cover pit of the vacuum manifold. Two additional washings $(200 \mu \mathrm{l} /$ well $)$ of the filter with buffer A containing $1 \mathrm{mg} / \mathrm{ml} \alpha 1$-acid glycoprotein were included to reduce further the nonspecific binding. Nonspecific binding was determined in the presence of $1 \mu \mathrm{M}$ nonradioactive RTX. Measurements of binding were determined in triplicate in each experiment, and each experiment was repeated at least three times. In each experiment $\left[{ }^{3} \mathrm{H}\right] \mathrm{RTX}$ binding curves were typically determined using five or six concentrations of the radioactive ligand. Binding was expressed as femtomoles per milligram of protein. Samples were equilibrated in scintillation fluid for a minimum of $10 \mathrm{hr}$ before measurement of radioactivity commenced, and each sample was counted for $5 \mathrm{~min}$. Binding data were analyzed by fitting to the following equation: $B=\left(B_{\max } \times L^{n}{ }_{\mathrm{H}}\right) /\left(K_{\mathrm{d}}+\right.$ $L^{n}{ }_{\mathrm{H}}$ ), where $L_{\mathrm{H}}$ is the concentration of the radioactive ligand, $B$ represents specifically bound [ $\left.{ }^{3} \mathrm{H}\right] \mathrm{RTX}, B_{\max }$ is the receptor density, $K_{\mathrm{d}}$ is the concentration of $\left[{ }^{3} \mathrm{H}\right] \mathrm{RTX}$ at which half of the receptors are occupied, and $n$ is the cooperativity index referred to as the Hill coefficient. Under these assay conditions, specific bound radioactivity at the $K_{\mathrm{d}}$ for wildtype VR1 was $\sim 650 \mathrm{dpm}$, and nonspecific binding was $\sim 150 \mathrm{dpm}$. Specific binding at the $K_{\mathrm{d}}$ thus represented $\sim 80 \%$ of the total binding.

Under our conditions, the filtration $\left[{ }^{3} \mathrm{H}\right] \mathrm{RTX}$ binding assay was satisfactory when the maximal concentration of the radioactive RTX did not exceed $1.5 \mathrm{~nm}$. Above that concentration, we preferred to use a centrifugation assay (Szallasi et al., 1992), which gives a lower level of nonspecific binding. This assay was used for quantitative comparison of the NML676FAP mutant and vector control cells. Both cell types were also assayed using the filtration method.

Intracellular calcium imaging. Activation of the VR1 channels results in an increase in intracellular calcium attributable to the high calcium permeability of these channels (Caterina et al., 1997). This response was harnessed to produce a fluorescence-based assay to determine the concentration dependence for agonist activation of VR1 expressed in mammalian cells. CHO cells expressing VR1 or the NML676FAP mutant were seeded into 96-well plates and grown to confluence. Wells were rinsed twice with Earle's balanced salt solution (EBSS), and then $200 \mu \mathrm{l}$ of EBSS containing the calcium indicator fluorescent dye Fluo3 $(5 \mu \mathrm{M}$; Molecular Probes, Eugene, OR) was added to each well. Plates were transferred to a temperature-controlled chamber in a multiwell laser spectrofluorimeter (FLIPR Fluorometric Imaging Plate Reader; Molecular Devices, Sunnyvale, CA) and illuminated at $488 \mathrm{~nm}$. Fluorescence was simultaneously imaged and quantified from each well (16-bit resolution) at $1 \mathrm{sec}$ intervals. After 5 or 10 control samples, various doses of capsaicin in EBSS and Fluo3 was rapidly and simultaneously equilibrated $(5 \mathrm{sec})$ in all wells to activate capsaicin receptors, and fluorescence responses were sampled. Agonist-induced fluorescence increases (corresponding to calcium elevation) were obtained after background subtraction. Data from eight wells were averaged (mean \pm SEM) at each concentration.

Western blot. CHO cells were transiently transfected and harvested in cold Tris buffer, $\mathrm{pH}$ 7.8. The cells were lysed in a solution containing 100 $\mathrm{mM}$ sodium phosphate, $10 \mathrm{~mm} \mathrm{KCl}, 1 \mathrm{~mm} \mathrm{MgSO}_{4}, \quad 50 \mathrm{~mm}$ $\beta$-mercaptoethanol, $2.5 \mathrm{~mm}$ EDTA, and $0.125 \%$ NP-40. Cell lysates 

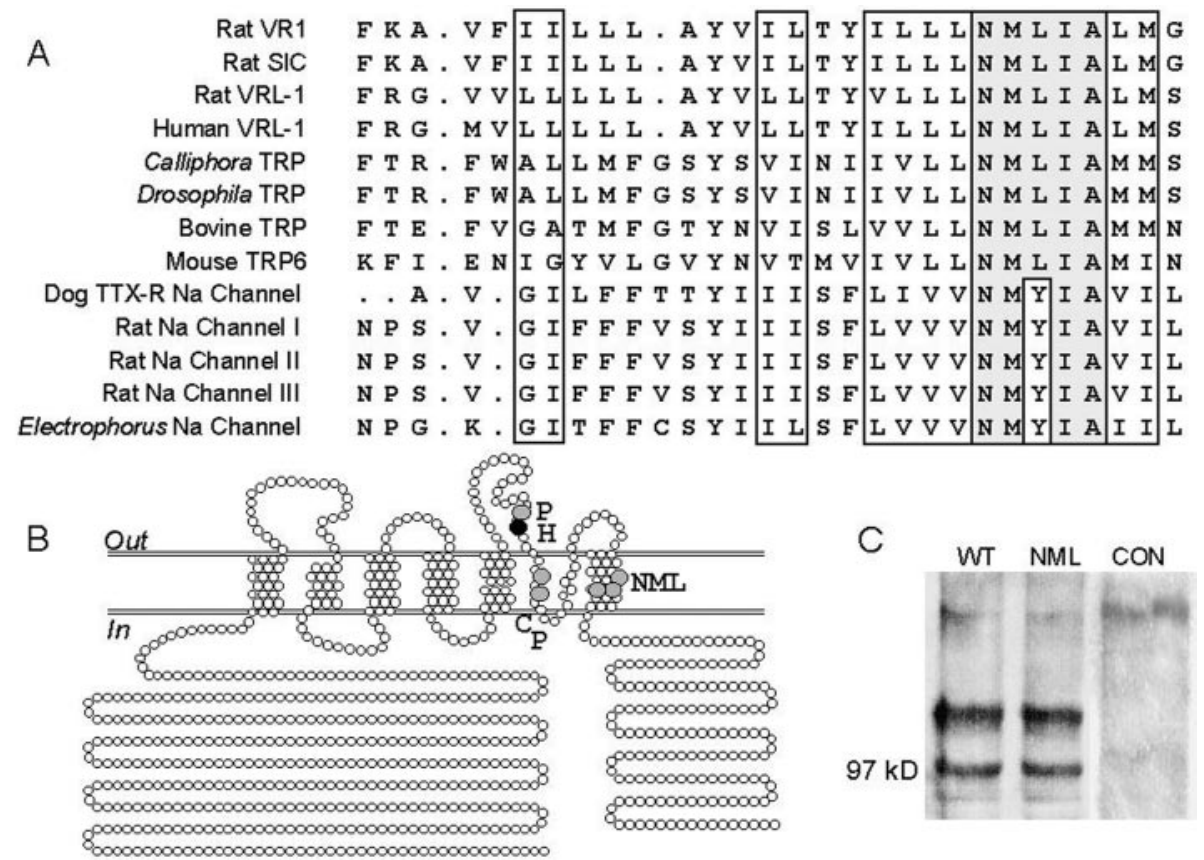
$(N M L)$, or pUC19 plasmid (CON) using the N-terminal VR1 antibody (1:1000 dilution) and enhanced chemiluminescence (Amersham Pharmacia Biotech). The molecular weight marker is indicated.

containing equal amounts of total protein were subjected to electrophoresis on a $7.5 \%$ polyacrylamide gel and transferred to an Immobilon membrane (Millipore). The presence of VR1 in the cell lysates was assayed using an N-terminal VR1 antibody (a gift from Aurora Guo and Robert Elde, University of Minnesota, Minneapolis, MN; 1:1000 dilution) and enhanced chemiluminescence (Amersham Pharmacia Biotech, Arlington Heights, IL).

Immunostaining. $\mathrm{CHO}$ cells were plated on glass coverslips coated with poly-L-lysine and transfected with either wild-type VR1 receptor or the NML676FAP mutant receptor along with the EGFP marker plasmid. Two days after transfection, the cells were washed with cold PBS, permeabilized, and fixed (4\% paraformaldehyde and $0.1 \%$ Triton X-100) on ice for $30 \mathrm{~min}$. Fixed cells were washed in cold PBS and incubated overnight at $4^{\circ} \mathrm{C}$ with the N-terminal VR1 antibody at a 1:1000 dilution in a PBS solution containing 3\% heat-inactivated horse serum, $1 \%$ bovine serum albumin, and $0.3 \%$ Triton X-100. The cells were washed extensively in cold PBS and incubated for $1 \mathrm{hr}$ with the Alexa 594 labeled secondary antibody (Molecular Probes) at a 1:400 dilution in a PBS solution containing 3\% bovine serum albumin and $0.3 \%$ Triton X-100. The cells were washed extensively in cold PBS and placed in a glassbottom chamber on an inverted microscope stage (Nikon Diaphot). The fluorescence imaging was performed using fluorescein (to detect EGFP) and rhodamine (to detect the Alexa 594 antibody) filter sets, and images were captured using a Pentamax cooled CCD camera (Princeton Instruments, Trenton, NJ).

\section{RESULTS}

The amino acid sequence of the cloned rat VR1 receptor predicts a topology that includes six transmembrane domains (Caterina et al., 1997). The extracellular sequence between the fifth and sixth predicted transmembrane domains is speculated to contain a reentrant "pore loop" domain by analogy with other ion channels, most notably potassium channels, for which experimental evidence exists to support this notion (Yellen et al., 1991; Yool and Schwarz, 1991). In our search for a functionally disabled receptor, we took three approaches to targeting mutations on the basis of analysis of the sequence and previous functional data in VR1.

We first sought regions of high sequence conservation that might confer fundamental properties on the assembled capsaicin receptor. Analysis of the primary sequence of VR1 revealed that the sixth transmembrane domain is highly homologous to that
Figure 1. A, Amino acid residues in the sixth transmembrane domain of the rat VR1 receptor are highly conserved. Rat SIC and rat VRL-1 are the recently cloned stretchinhibitable nonselective cation channel and the vanilloid receptor like protein 1 , respectively. The various TRP sequences are from the proteins in the transient receptor potential family. The sodium channel sequences are from the sixth transmembrane region of the different voltage-gated sodium channels. Shaded boxes indicate identical amino acids, and open boxes show the highly conserved amino acids. $B, \mathrm{Pu}-$ tative membrane topology of the rat VR1 receptor. The locations of amino acids that were mutated in the rat VR1 receptor are indicated. Shaded circle $P$ in the third outer loop represents the P613L mutation. Shaded circles $C$ and $P$ in the putative pore region in the membrane represent the CP621GL double mutant, and shaded circles $N, M$, and $L$ in the sixth transmembrane region represent the NML676FAP mutant. Solid circle $H$ represents the H614T mutation. Mutated VR1 receptors were characterized by both restriction enzyme mapping and DNA sequencing. $C$, Western blot analysis of $\mathrm{CHO}$ cells transfected with wild-type rat VR1 receptor $(W T)$, NML676FAP mutant of the $\alpha$ subunits of several voltage-gated sodium channels as well as the transient receptor potential (TRP) family of store-operated calcium channels (Fig. $1 A$ ). In particular, a stretch of five amino acids (NMLIA) is totally conserved across all VR1- and TRPrelated members and differs only in a leucine-to-tyrosine substitution in sodium channels. To examine the role of these highly conserved residues, we used site-directed mutagenesis to generate a rat VR1 mutant (henceforth referred to as NML676FAP) with three substitutions at positions $676($ Asn $\rightarrow$ Phe), 677 $(\mathrm{Met} \rightarrow$ Ala) and 678 (Leu $\rightarrow$ Pro). The substitutions were chosen to be rather conservative to favor assembly and membrane expression of the mutant. Second, we reasoned that ligand-induced gating might involve conformational changes in flexible regions of the peptide near the pore domain. We therefore generated two other VR1 mutants with substitutions at proline residues near the putative pore loop region. One of the mutants (henceforth referred to as $\mathrm{P} 613 \mathrm{~L}$ ) has a single substitution at position 613 $($ Pro $\rightarrow$ Leu), whereas the other (henceforth referred to as CP621GL) has substitutions at positions 621 (Cys $\rightarrow$ Gly) and 623 (Pro $\rightarrow$ Leu). These residues were chosen assuming mutation might constrain the peptide chain flexibility often conferred by proline residues, which might underlie a gating conformational change. Finally, taking note of the activation of VR1 by protons with an apparent $\mathrm{p}_{\mathrm{Ka}}$ of $\sim 5.4$ (Tominaga et al., 1998), we mutated the only histidine residue in VR1 located in the N-terminal region of the putative pore loop domain at position 614 (His $\rightarrow$ Thr). The rationale was that titration of His ${ }^{614}$ might underlie proton activation, and a mutation might render the receptor insensitive to $\mathrm{pH}$. The relative positions of these mutated residues in the rat VR1 receptor are indicated in Figure $1 B$. All mutants were sequenced to confirm the substitutions.

The function of wild-type and mutated VR1 receptors was compared in transiently transfected $\mathrm{CHO}$ cells by measuring whole-cell current responses to $1 \mu \mathrm{M}$ capsaicin (CAP), protons, $\mathrm{pH}$ 5.0, and $50 \mathrm{~nm}$ RTX. Representative current responses in the absence of extracellular calcium (to reduce desensitization; Ko- 


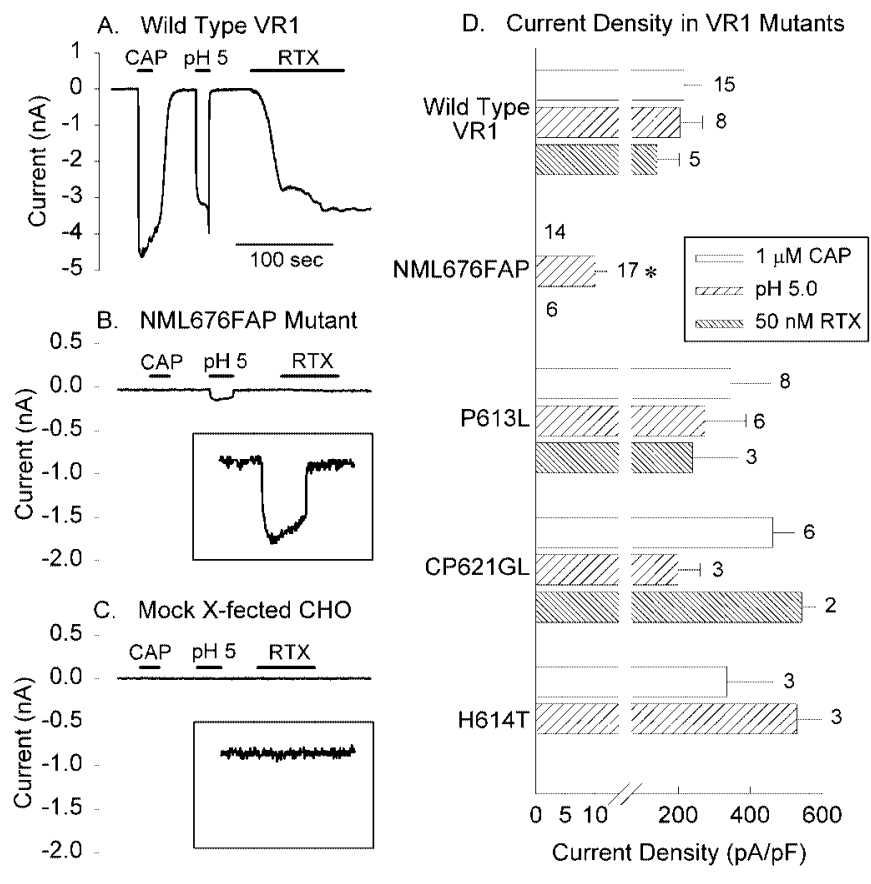

Figure 2. Comparison of wild-type and mutant VR1 receptor function in $\mathrm{CHO}$ cells. $A$, Wild-type VR1 responds with inward currents to $1 \mu \mathrm{M}$ CAP, pH 5.0, and 50 nM RTX. $B$, In contrast, $\mathrm{CHO}$ cells expressing the NML676FAP mutant do not respond to $1 \mu \mathrm{M}$ CAP or $50 \mathrm{~nm}$ RTX but respond partially to a $\mathrm{pH}$ of 5.0 (inset, proton response on a magnified scale; calibration: $200 \mathrm{pA}, 200 \mathrm{msec}$ ). $C$, Control cells transfected with vector alone do not respond to any agonist. All experiments were performed in calcium-free external solution to prevent desensitization. $D$, Mean current density \pm SEM of responses of wild-type VR1 and of NML676FAP, P613L, CP621GL, and H614T mutant receptors to capsaicin $(1 \mu \mathrm{M}$; white bars), $\mathrm{pH} 5.0$ (hatched bars), or resiniferatoxin $(50 \mathrm{nM}$; gray bars). Note the break in the current density axis to emphasize the proton response of the NML676FAP mutant. * Significant difference $(p<$ 0.005) between responses of the NML676FAP mutant and nontransfected $\mathrm{CHO}$ cells.

plas et al., 1997) are shown for a CHO cell transfected with the wild-type VR1 receptor (Fig. $2 A$ ) or one expressing the NML676FAP mutant receptor (Fig. 2B). Cumulative results represented as current density are summarized for all experiments in Figure $2 D$. As expected, wild-type receptors responded robustly to all three agonists. In contrast, neither $1 \mu \mathrm{M}$ capsaicin $(n=14)$ nor 50 nм RTX $(n=6)$ evoked responses from the NML676FAP mutant in any cell examined (Fig. $2 B, D$ ). Interestingly, protons consistently evoked a small but significant inward current response in cells expressing the NML676FAP mutant (Fig. 2B) that was 20-fold smaller than proton responses of wild-type VR1 (Fig. $2 D$ ). Although small, the proton responses of the NML676FAP mutant could easily be distinguished from background responses observed in nontransfected or mock-transfected CHO cells (Fig. $2 C)$. The average proton response of the NML676FAP mutant $(10.0 \pm 2 \mathrm{pA} / \mathrm{pF} ; n=17)$ was statistically greater than that of mock transfected $\mathrm{CHO}$ cells $(1.0 \pm 0.4 \mathrm{pA} / \mathrm{pF} ; n=8 ; p<0.005$, Student's $t$ test), clearly indicating that the VR1 mutant conducts the proton-activated current. This marked dichotomy of sensitivity to vanilloids and protons suggests differences in the activation mechanisms for the two classes of agonist, as has been proposed previously (Jordt et al., 2000).

In contrast to the disruption of responses in the NML676FAP mutant, cells transfected with either the P613L or the CP621GL mutant receptor gave robust responses (representative data not shown) to CAP, pH 5.0, and RTX (Fig. 2D). Interestingly, when compared with wild-type VR1, the CP621GL mutant gave larger responses to CAP and $\mathrm{RTX}(p<0.01)$ but not to protons. Nonetheless, mutation of the proline residues flanking the lone histidine residue near the putative pore domain failed to prevent gating of the receptor by any of the three agonists.

Activation of VR1 by protons is an intriguing phenomenon, because it contributes to the emerging concept of VR1 as a multimodal sensory transducer (Tominaga et al., 1998). The $\mathrm{pH}$ sensitivity of direct proton activation of VR1 is complicated because of interactions with other agonists such as capsaicin and heat to yield titration curves with apparent $\mathrm{p}_{\mathrm{Ka}}$ values between 5.0 and 6.0 (Tominaga et al., 1998). This range of $\mathrm{pH}$ is consistent with the involvement of a histidine residue in transducing proton binding to activation of VR1. The only histidine residue in the rat VR1 sequence (His ${ }^{614}$ ) is located in the extracellular loop adjacent to the putative pore loop domain. We mutated this residue (H614T) and observed that when the mutant receptor was expressed, both capsaicin $(1 \mu \mathrm{M})$ and protons, $\mathrm{pH}$ 5.0, effectively activated currents at densities undiminished from those of wildtype VR1 (Fig. 2D), suggesting that His ${ }^{614}$ is not critical for activation by protons. A similar finding was recently reported by Jordt et al. (2000) with a H614Q mutant. We further examined whether this residue might play a role in the sensitization of agonist responses by $\mathrm{pH}$. Jordt et al. (2000) have reported that titration of a nearby glutamine residue $\left(\mathrm{Glu}^{600}\right)$ does not directly gate VR1 by protons but regulates sensitization of VR1 to other agonists (e.g., capsaicin and heat). We have found that in cells expressing wild-type VR1 but not in cells expressing the H614T mutant, protons (i.e., $\mathrm{pH}$ 5.0), markedly sensitized responses to capsaicin (data not shown). Thus as with Glu ${ }^{600}$ (Jordt et al., 2000) His $^{614}$ is not the site of direct proton activation but is critical to sensitization of other agonists by low $\mathrm{pH}$.

Because the strategy to mutate highly conserved residues in the sixth transmembrane domain resulted in abolition of capsaicin responses, we pursued characterization of NML676FAP and assessment of its potential as a dominant negative mutant.

\section{The NML676FAP mutant receptors are expressed in the membrane}

To determine whether the failure to observe responses of the NML676FAP mutant to CAP or to RTX was attributable to aberrant expression or trafficking to the plasma membrane, cells were cotransfected with either wild-type VR1 or NML676FAP mutant receptors and a plasmid encoding EGFP as a transfection marker. Transfected and control cells were immunostained using an antibody raised against the N-terminal region of rat VR1 (Guo et al., 1999). Using fluorescence microscopy, we observed that cells transfected with either the VR1 wild-type or mutant receptors (identified by EGFP coexpression) exhibited similar expression strength and patterns (Fig. 3), whereas control cells did not stain above background (data not shown). In addition, Western blot analysis using the VR1 N-terminal antibody revealed bands that were similar in size and intensity in cell lysates from $\mathrm{CHO}$ cells transfected with wild-type VR1 or the NML676FAP mutant but not from control nontransfected $\mathrm{CHO}$ cells (Fig. 1C). The observed sizes of the bands (glycosylated and unglycosylated forms) are in agreement with previous reports (Tominaga et al., 1998; Guo et al., 1999; Kedei et al., 2001). Taken together with the retention of proton responses, these results suggest that the dramatic loss of vanilloid responses is attributable to disruption of 


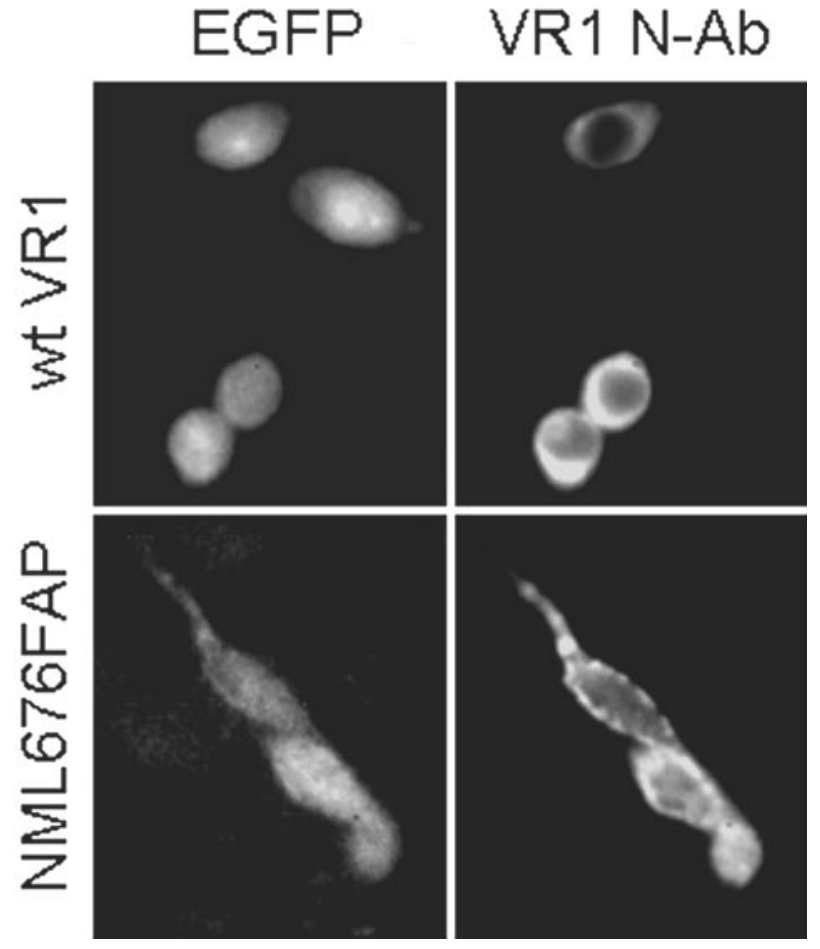

Figure 3. The NML676FAP mutant is expressed and localized similarly to wild-type VR1 when transiently transfected in CHO cells. Shown are fluorescence images of EGFP (left) and a secondary antibody labeling a VR1 N-terminal antibody (right) in cells cotransfected with EGFP and either wild-type VR1 (top) or the NML676FAP mutant (bottom). Images were obtained as described in Materials and Methods.

channel function in the NML676FAP mutant rather than abnormal synthesis, processing, or membrane insertion.

\section{The NML676FAP mutation does not shift the capsaicin dose-response relationship}

To determine whether the absence of vanilloid responsiveness in this mutant simply reflects a shift in the concentration dependence of agonist sensitivity, we performed two types of experiments. Measuring currents in whole-cell recording mode, we attempted to activate the NML676FAP mutant receptor with much higher concentrations of capsaicin (30 and $100 \mu \mathrm{M})$ or RTX $(1 \mu \mathrm{M})$ but in all cases failed to activate currents (data not shown). In a second series of experiments, we took advantage of the high calcium permeability of VR1 (Caterina et al., 1997; Koplas et al., 1997) to compare changes in intracellular calcium concentration evoked by application of various concentrations of capsaicin. These experiments were performed on $\mathrm{CHO}$ cells cultured in 96-well plates, transfected with wild-type or mutant VR1, and loaded with the calcium indicator dye Fluo3. As can be seen in Figure $4 A$, the application of capsaicin to cells expressing wildtype VR1 results in a rapid increase in intracellular calcium, the rate of which increased with increasing capsaicin concentration. A similar experiment on cells expressing the NML676FAP mutant failed to demonstrate a significant rise in intracellular calcium even at capsaicin concentrations as high as $100 \mu \mathrm{M}$ (Fig. $4 B$, inverted triangles). Thus both electrophysiological and calcium imaging experiments over a large concentration range indicate that the NML676FAP mutation did not simply shift the capsaicin dose-response curve; rather, the mutant receptor is unable to activate in response to vanilloid agonists.
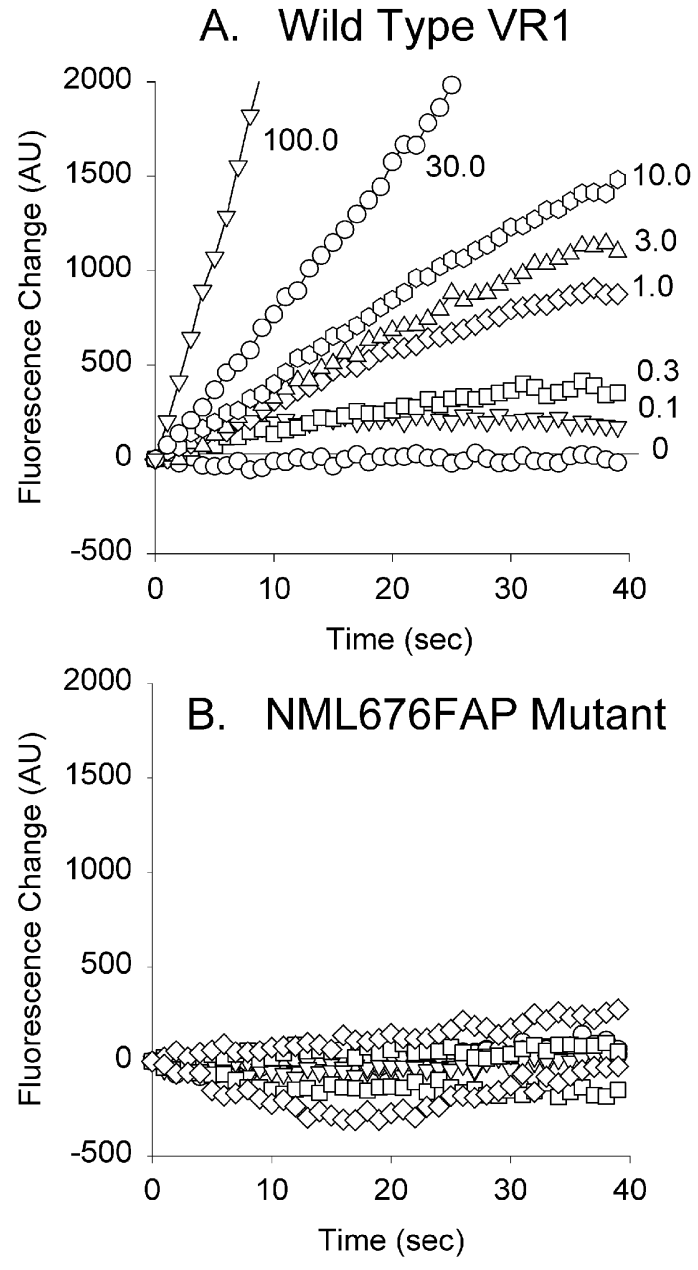

Figure 4. The NML676FAP mutant fails to respond to even high concentrations of capsaicin. Shown are Fluo3 fluorescence responses (arbitrary units) of $\mathrm{CHO}$ cells expressing wild-type VR1 $(A)$ or the NML676FAP mutant $(B)$ assessed in 96-well plates using an FLIPR spectrofluorimeter. Each symbol (identical for $A, B$ ) represents the average fluorescence of eight wells at the indicated concentration of capsaicin (micromolar).

\section{The vanilloid binding site is intact but altered in the NML676FAP mutant}

The competitive vanilloid antagonist capsazepine has been reported to inhibit the activation of the VR1 receptor by capsaicin, heat, and protons (Tominaga et al., 1998). To determine the receptor specificity of the residual proton response in the NML mutant, we tested the ability of $10 \mu \mathrm{M}$ capsazepine to antagonize the proton response. Figure 5 shows that the response elicited by a $\mathrm{pH}$ of 5.0 in a $\mathrm{CHO}$ cell expressing either wild-type VR1 (Fig. $5 A$ ) or the NML676FAP mutant (Fig. $5 B$ ) is strongly but not completely inhibited by $10 \mu \mathrm{M}$ capsazepine. This result is consistent with previous observations (Tominaga et al., 1998) for VR1 and confirms that the residual proton response in the mutant reflects activation of the VR1 mutant rather than an endogenous unidentified proton receptor.

To confirm that the vanilloid binding site is intact, we compared $\left[{ }^{3} \mathrm{H}\right] \mathrm{RTX}$ binding in wild-type and NML676FAP mutant receptors. $\mathrm{CHO}$ cell cultures were transfected with equivalent amounts of plasmid DNA encoding wild-type VR1 (wtVR1), NML676FAP, or pUC19 (control plasmid). Binding parameters were determined in membrane pellets from each culture as de- 

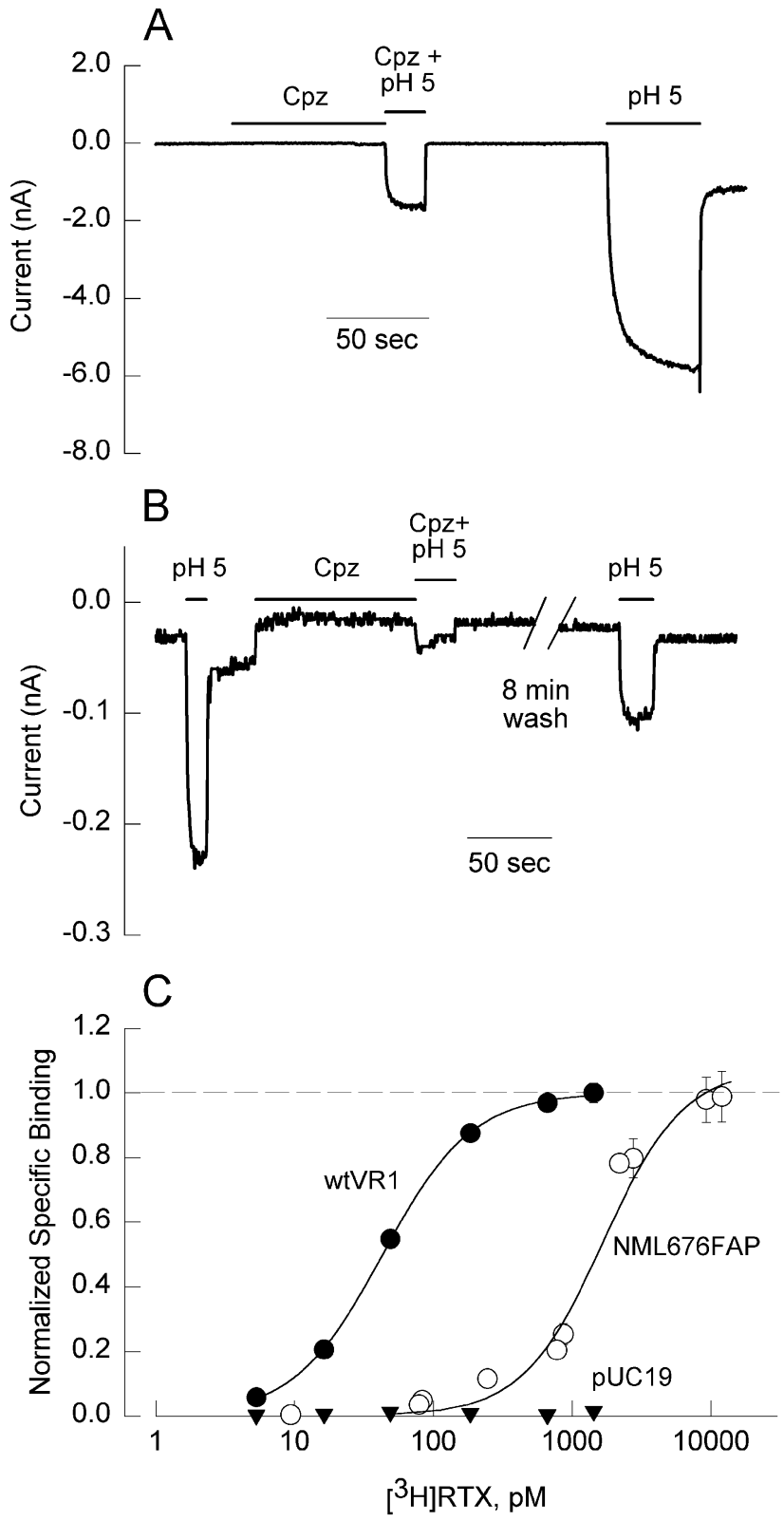

Figure 5. The vanilloid binding site is intact but altered in the NML676FAP mutant. The inward current elicited by protons $(\mathrm{pH} 5.0$ solution) is inhibited by $10 \mu \mathrm{M}$ capsazepine ( $C p z)$ in CHO cells expressing either the wild-type VR1 receptor $(A)$ or the NML mutant receptor $(B)$. The inhibition is reversible, because the proton-induced inward currents recover after washout of $\mathrm{Cpz}$. The experiment was performed in an external solution lacking calcium to reduce desensitization. Calibration, $50 \mathrm{sec}$. $C$, Specific binding of $\left[{ }^{3} \mathrm{H}\right] \mathrm{RTX}$ to $\mathrm{CHO}$ cell membranes expressing wild-type VR1 ( filled circles), the NML676FAP mutant (open circles), or pUC19 as a control (filled inverted triangles) normalized to the $B_{\max }$ values in each case. Curves represent fits of the Hill equation to the data as described in Materials and Methods with the following parameters: wtVR1, $B_{\max }=139.4 \pm 3.1 \mathrm{fmol} / \mathrm{mg}$ protein; $K_{\mathrm{d}}, 43 \mathrm{pM}$; and $n=1.36$; NML676FAP, $B_{\max }=260.2 \pm 15.6 \mathrm{fmol} / \mathrm{mg}$ protein; $K_{\mathrm{d}}, 1670 \mathrm{pM}$; and $n=1.51$.

scribed in Materials and Methods. RTX binding was detected to both wild-type and mutant receptors at comparable densities $\left(B_{\max }\right.$ values of $139.4 \pm 3.1$ and $260.2 \pm 15.6 \mathrm{fmol} / \mathrm{mg}$ protein for wtVR1 and NML676FAP receptors, respectively). No significant binding was observed in the pUC19-transfected control cells. In contrast, cells expressing wild-type VR1 exhibited an apparent affinity of $43 \mathrm{pM}$, whereas cells expressing the NML676FAP mutant bound RTX with $\sim 35$-fold lower affinity $\left(K_{\mathrm{d}}, 1444 \mathrm{pM}\right.$; Fig. $5 C$ ). These data suggest that the vanilloid binding site is intact in the NML676FAP mutant but exhibits a much lower affinity for RTX. This shift in the binding curve, although large, is not sufficient to account for the absence of vanilloid responses in the mutant, because RTX concentrations as high as $1 \mu \mathrm{M}$ failed to activate the mutant receptor.

\section{Desensitization properties of the NML676FAP mutant}

Consistent with observations in native neurons (Docherty et al., 1996; Liu and Simon, 1996), the cloned wild-type VR1 receptor undergoes acute desensitization and tachyphylaxis (Caterina et al., 1997). We have confirmed this for VR1 expressed in $\mathrm{CHO}$ cells (Fig. 6A) and have also observed that proton responses of wild-type VR1 undergo similar desensitization (Fig. 6C). As observed previously in neurons (Koplas et al., 1997), both the acute desensitization and tachyphylaxis of the VR1 receptor are dependent on calcium, because removal of extracellular calcium inhibits both forms of desensitization (Fig. 6B,D).

During these experiments, we noted the consistent appearance of a "tail" current, a transient increase in inward current, on return to a $\mathrm{pH}$ of 7.4 after proton stimulation, which was particularly prominent in calcium-free solutions (Fig. 6D). We speculate that protons can both activate and block VR1 channels and that the tail current reflects relief of the block on removal of protons. Consistent with this suggestion, changes in unitary conductance of single capsaicin-activated channels by low $\mathrm{pH}$ have been reported recently in trigeminal ganglion neurons (Baumann and Martenson, 2000).

To assess whether the proton response of the NML676FAP mutant exhibited similar desensitization, we repetitively applied $\mathrm{pH} 5.0$ solution to cells expressing this mutant. Consistent with the behavior of wild-type VR1, the proton response of the NML676FAP mutant exhibited both acute desensitization and tachyphylaxis (Fig. 6E). In addition, the tachyphylaxis was calcium-dependent, because it was nearly absent in calcium-free solutions (Fig. 6F).

\section{The NML676FAP mutant acts as a dominant negative subunit}

The capsaicin receptor has been assumed to exist as a multimeric complex of VR1 receptor subunits (Caterina et al., 1997; Szallasi and Blumberg, 1999). A recent biochemical study using coimmunoprecipitation and immunoblot of differentially tagged VR1 proteins indicates oligomerization (Kedei et al., 2001); however, functional evidence for multimerization is lacking. The nonf unctional NML676FAP mutant affords an opportunity to experimentally evaluate this assumption by testing for dominant negative properties by coexpression with wild-type VR1. Expression plasmids encoding the NML676FAP mutant and wild-type VR1 were cotransfected (at 1:1 stoichiometry) into CHO cells, and CAPinduced currents were measured and compared with those of cells transfected with only wild-type VR1 receptors (Fig. 7A). The mutant dramatically reduced (40-fold) the current density when coexpressed with the wild-type receptor, suggesting that the functional VR1 receptor is a multimeric complex and that one or more mutant subunits in a complex can render the receptor insensitive to capsaicin. This observation was confirmed by transiently transfecting the NML676FAP mutant receptor into a clonal CHO cell line stably expressing wild-type VR1 receptors 
A
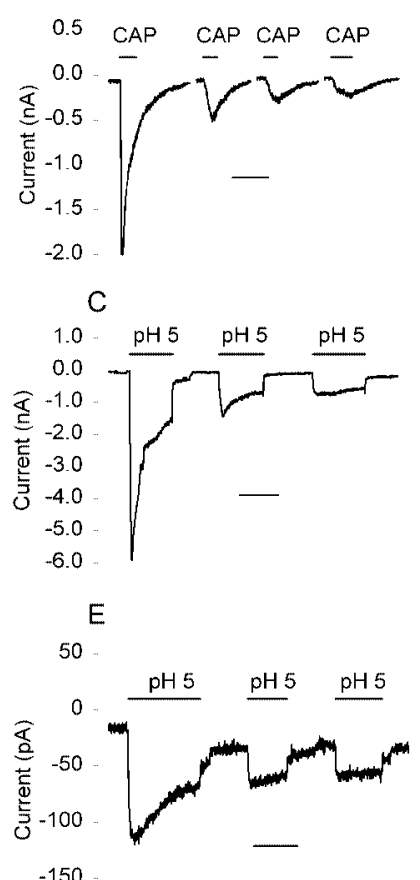

$-150$

Figure 6. Calcium-dependent desensitization of the inward currents induced by capsaicin and protons. CHO cells expressing the wild-type VR1 receptor $(A-D)$ exhibit acute desensitization and tachyphylaxis when treated with $1 \mu \mathrm{M}$ CAP $(A)$ or a pH 5.0 solution $(C)$ in the presence of external calcium. Removal of calcium from the external solution blocks desensitization $(B, D)$. The proton response in $\mathrm{CHO}$ cells transfected with the NML676FAP mutant also exhibits desensitization in the presence $(E)$ but not in the absence $(F)$ of calcium in the external solution. Calibration, $50 \mathrm{sec}$.

and observing a similar reduction in CAP responsiveness (Fig. $7 B$ ). As a control for the transfection process, wild-type VR1 was transiently transfected into this stable VR1 CHO cell line, and a modest augmentation of the response to capsaicin was observed (Fig. $7 B$ ) as expected. In view of the proton responses retained by the NML676FAP mutant, we also examined its ability to reduce normal proton responses when coexpressed with wild-type VR1. We observed reductions in proton responses of VR1-expressing cells comparable with those seen for CAP responses (Fig. 7B). These results reveal the NML676FAP mutant to be an effective dominant negative subunit that can be used to disrupt function of endogenous VR1 receptors.

\section{Functional stoichiometry of the vanilloid receptor probed with the NML676FAP mutant}

To assess the functional stoichiometry of the vanilloid receptor, we followed an approach originally implemented for voltagegated potassium channels (MacKinnon et al., 1993) and previously used with minK and inward rectifier potassium channels (Tzounopoulous et al., 1995; Tinker et al., 1996). Using a dominant negative mutant, one can compare the function of a channel population comprising various combinations of wild-type and mutant subunits to predictions of function assuming the population represented a binomial distribution of the possible assembled combinations. Here we assume that the functional vanilloid receptor is a multimer of VR1 subunits and that incorporation of one or more nonf unctional mutant subunits is sufficient to abolish function of the assembled receptor. The stoichiometry of the
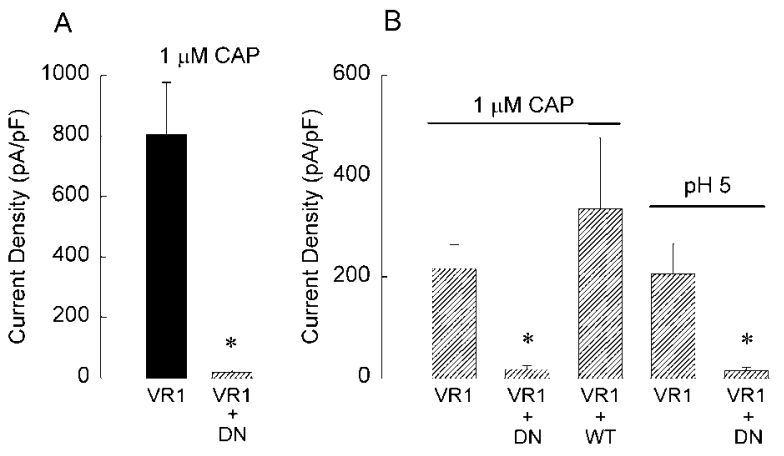

Figure 7. The NML676FAP mutant functions as a dominant-negative subunit. $A, \mathrm{CHO}$ cells were transiently transfected with either wild-type VR1 receptor $(V R 1)$ or equal amounts of wtVR1 and NML676FAP mutant receptors $(V R 1+D N)$. Inward current density elicited by $1 \mu \mathrm{M}$ capsaicin in CHO cells transfected with wild-type VR1 $(n=3)$ was significantly greater than in cells cotransfected with VR1 + DN $(n=12$; ${ }^{*} p<0.001$, Student's $t$ test). $B$, Inward currents elicited by $1 \mu \mathrm{M}$ capsaicin or protons, $\mathrm{pH} 5.0$, in a CHO cell clone stably expressing the rat VR1 receptor $(n=15)$ were significantly attenuated by the transiently transfected mutant receptor (capsaicin responses of VR1 $+\mathrm{DN}, n=12$; proton responses of VR1 $+\mathrm{DN}, n=8 ;{ }^{*} p<0.002$, Student's $t$ test). In contrast, transient transfection of wild-type VR1 receptor into the CHOVR1 clone $(V R 1+W T)$ had no significant effect on capsaicininduced inward current $(n=3)$. The current measurements were done in calcium-free external solution. All values of currents were divided by membrane capacitance (picoamperes per picofarads) to normalize for cell size differences.

assembled receptor can be estimated by measuring function in cells in which the relative expression of wild-type and mutant subunits is titrated by the ratio of respective transfected cDNA. We therefore transiently transfected $\mathrm{CHO}$ cells with various ratios of wild-type and NML676FAP mutant cDNA, maintaining a total DNA concentration of $1.4 \mu \mathrm{g} /$ well, and measured both current density in response to $1 \mu \mathrm{M}$ capsaicin in single cells and $\left[{ }^{3} \mathrm{H}\right] \mathrm{RTX}$ binding in cell populations. To determine whether variations in the amount of transfected VR1 cDNA were actually reflected in corresponding changes in VR1 protein expression, we performed a control experiment in which ratios of wild-type VR1 and a control plasmid (pUC19) were transfected at a total constant DNA concentration of $4 \mu \mathrm{g} / \mathrm{sample}$, and receptor density was determined from $\left[{ }^{3} \mathrm{H}\right] \mathrm{RTX}$ binding. As shown in Figure $8 A$, the measured $B_{\max }$ values matched the predictions from the amount of DNA (normalized) over a 16-fold range of VR1 plasmid concentration, suggesting that receptor expression faithfully tracked DNA concentration for the levels we used. Current density in cells expressing increasing percentages of NML676FAP relative to wild-type VR1 progressively declined as expected (Fig. $8 B$, filled circles). Assuming that both mutant and wild-type subunits expressed equally, that receptors were assembled and distributed binomially, and that a single mutant subunit was sufficient to block function, predictions of the expected current density were generated for several stoichiometries. The data are consistent with the prediction that the functional vanilloid receptor exists as a tetramer, whereas dimeric, trimeric (data not shown), and octameric receptors do not fit the data set (Fig. 8B, solid lines). Although the assumption of a "one-hit" disruption of function by a single mutant subunit is the simplest and is consistent with previous studies on potassium channels, we reasoned that the common view that two capsaicin molecules activate the receptor (Hill coefficient values, $\sim 2$ ) suggested that two mutant subunits might be required to abolish function. The prediction of a tetrameric recep- 
Figure 8. Assessment of capsaicin receptor functional stoichiometry. $A,\left[{ }^{3} \mathrm{H}\right] \mathrm{RTX}$ binding was measured in $\mathrm{CHO}$ cells expressing different ratios of wild-type VR1 and a control plasmid, pUC19, transfected at a constant cDNA per sample of 4.0 $\mu \mathrm{g}$. Measured $B_{\max }$ values are plotted against predicted $B_{\max }$ values normalized at the lowest wildtype VR1 concentration $(0.23 \mu \mathrm{g})$. Numbers for each data point indicate concentrations of wild-type VR1 cDNA used, and the solid line represents identity $($ slope $=1.0) . B$, Current density values for capsaicin $(1 \mu \mathrm{M})$-induced currents in $\mathrm{CHO}$ cells transfected with different ratios of wild-type VR1 and NML676FAP plotted against the percentage of mutant cDNA. Data points represent mean \pm SEM values of $8,4,8,4,9$, and 13 measurements, respectively, for increasing percentage of mutant subunit. Lines represent predictions (scaled to the maximum current density) of a binomial distribution of assembled subunit combinations according to:

$$
I / I_{\mathrm{O}}=\sum_{i=0}^{n} C_{i}^{n} \cdot x^{n-i} \cdot(1-x)^{i},
$$

where $C=n ! / i !(n-i) !, n$ is the subunit stoichiometry, $i$ is number of required subunits to block function -1 , and $x$ is the fraction of wild-type subunits expressed of the total. Solid lines represent $n$ values of 2, 4, and 8 for $i=1$, and the dashed line corresponds to $n=4$ and $i=2$ (i.e., a tetrameric channel requiring two mutant subunits to
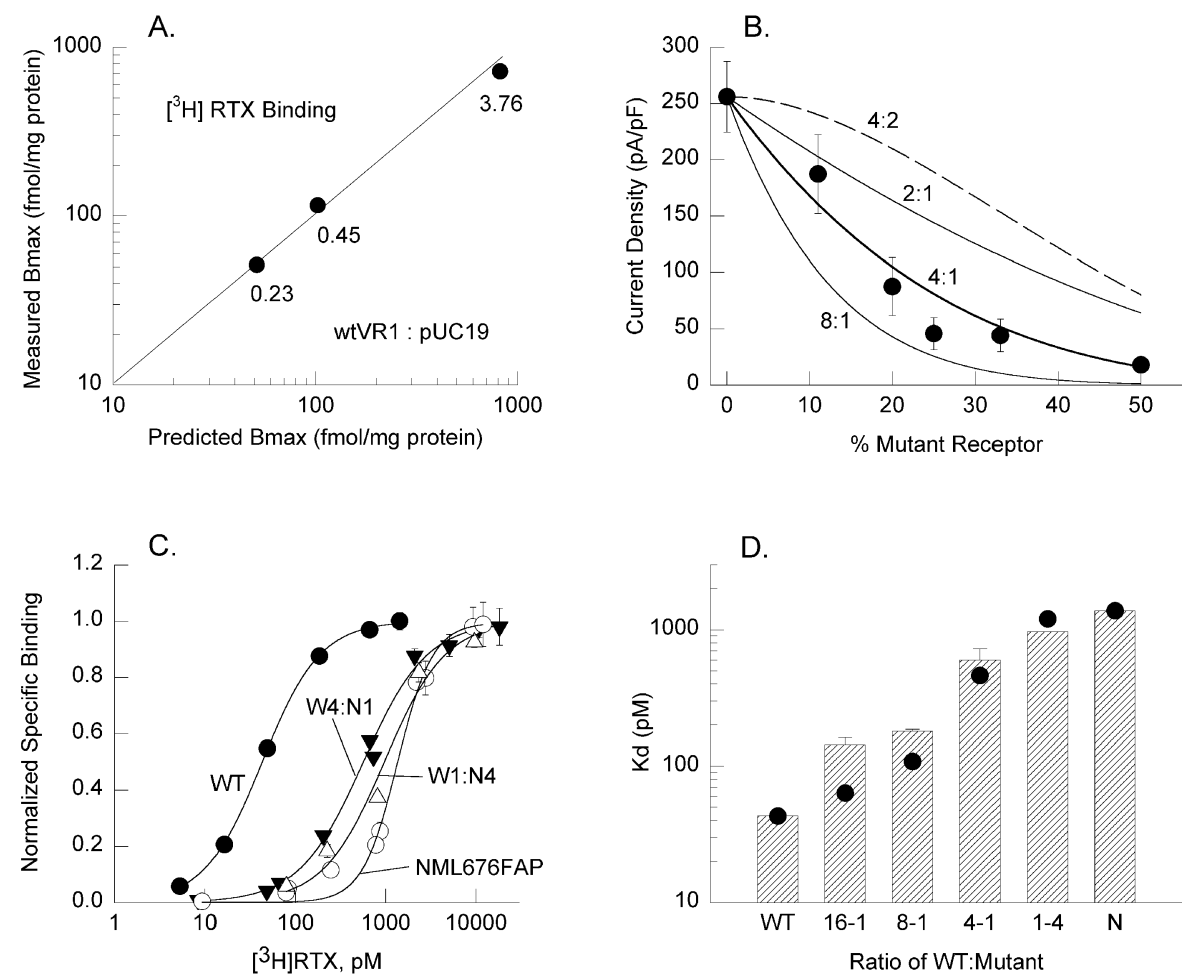

block function). $C$, Specific binding of $\left[{ }^{3} \mathrm{H}\right] \mathrm{RTX}$ to CHO cell membranes expressing ratios of wild-type VR1 to NML676FAP of 1:0 ( filled circles), 0:1 (open circles), 4:1 ( filled inverted triangles), or 1:4 (open triangles) normalized to the $B_{\max }$ values in each case. Curves represent fits of the Hill equation to each data set. $D, K_{\mathrm{d}}$ values derived from Hill equation fits to $\left[{ }^{3} \mathrm{H}\right] \mathrm{RTX}$ binding curves for CHO cells expressing wild-type VR1, the NML676FAP mutant, or the indicated ratios of wild type to mutant. Bars are mean \pm SEM values for two or three measurements in each case. Solid circles represent the predictions for a population of tetrameric receptors with binomially distributed assembly combinations assuming a single mutant subunit is sufficient to change the RTX affinity to that of the homomeric NML676FAP mutant receptor.

tor requiring two dominant negative subunits to disrupt function dramatically overestimated the observed current density for all transfection ratios (Fig. 8B, dashed line). For such a "two-hit" model to be consistent with our experimental data, we found that an octamer was the minimum oligomer required (fit not shown).

Because receptors assembled from only NML676FAP mutants exhibit significantly lower affinity for $\left[{ }^{3} \mathrm{H}\right] \mathrm{RTX}$, we also assessed changes in the $K_{\mathrm{d}}$ for receptors assembled from different ratios of expressed mutant and wild-type subunits. Leftward shifts in the binding curves (toward wild-type VR1 behavior) were observed with increasing expression of the wild-type subunit (Fig. $8 C$ ). The binding for mixtures of wild-type and mutant subunits exhibited cooperativity but somewhat less than observed for the mutant (average Hill coefficient values of 1.36, 1.28, 1.24, and 2.2 were measured for ratios of wild type to mutant of 1:0, 1:4, 4:1, and $0: 1$, respectively). The $K_{\mathrm{d}}$ values obtained by fitting the observed binding curves for each ratio of wild-type to mutant receptor are represented in Figure $8 D$, bars. Using the $K_{\mathrm{d}}$ values for cells expressing either wild-type or mutant subunits alone as limits, we calculated the expected $K_{\mathrm{d}}$ values for a tetrameric receptor in which a single mutant subunit confers mutant affinity by the binomial distribution (Fig. 8D, filled circles). For ratios of wildtype to mutant subunit expression of $1: 4,4: 1$, and $8: 1$, the observed $K_{\mathrm{d}}$ values are in good agreement with the model. For much larger expressed ratios of wild-type VR1 (16:1), the measured affinity is closer to that of the mutant than expected from the tetramer prediction. This difference may reflect a preferential assembly of heteromeric receptors over wild-type homomeric receptors. One might have expected the opposite, namely an observed affinity much closer to that of wild type, considering the possibility that with a 16-fold excess of wild-type plasmid, a subpopulation of cells that did not transfect with mutant DNA might only express homomeric wild-type receptors. In any event, changes in relative expression of the mutant and wild-type subunits confer changes in current density and RTX affinity consistent with a multimeric receptor, most likely a tetramer.

\section{DISCUSSION}

In this study, our primary goal was to develop a dominant negative form of VR1. This goal guided our focus on initial mutations in a highly conserved domain in the sixth transmembrane segment, in a proline-flanked region near the pore domain with potential flexibility to contribute to gating, and in the single histidine residue speculated to contribute to activation of the receptor by protons. We have succeeded in this goal with one of the mutants (NML676FAP) that not only fails to respond to capsaicin when expressed alone but also disrupts function of wild-type VR1. Moreover, this dominant negative behavior provides the first functional evidence that the capsaicin receptor is actually a multimeric complex of VR1 subunits.

Support for the multimeric nature of the capsaicin receptor has recently appeared in the form of biochemical evidence for protein oligomers of VR1 in perfluro-octanoic acid-PAGE (Kedei et al., 2001). Oligomers of 2,3,4, and higher were observed for cloned VR1 expressed in mammalian cells as well as native VR1 from dorsal root ganglia with a tetramer appearing as the most prominent multimer in several cases. This agrees with our functional data indicating that, as widely speculated, a tetrameric vanilloid 
receptor is the most likely stoichiometry of subunit assembly. Specifically, suppression of capsaicin-gated currents by increasing the expression of the dominant negative NML676FAP mutant was most consistent with a model in which a single mutant subunit of a tetrameric receptor totally blocked function. Although inherent limitations of the protein separation technology preclude an accurate assessment of the higher-order oligomers documented by Kedei et al. (2001), the possibility cannot be excluded that native capsaicin receptors of higher stoichiometry exist. In this regard, assembly of homomeric minK channels has been estimated to involve at least 14 subunits (Tzounopoulous et al., 1995). Our observations, however, place a mechanistic constraint on the coassembly of dominant negative and wild-type VR1 subunits in such a large receptor, such that more than one mutant would have to contribute to the final receptor for agonist activation to be abrogated. Indeed, our analysis suggests that two mutants in an octameric receptor would be required to reasonably account for the observed functional interference. Such a model would be consistent with pharmacological cooperativity for vanilloid activation of the receptor (Hill coefficient values near 2) and cannot be definitively ruled out by the present evidence.

How does the NML676FAP mutant disrupt function of the assembled receptor? This question cannot be answered completely, but several of our observations on its behavior when expressed alone suggest a general mechanism. The phenotype exhibited by the NML676FAP mutant could reflect an inability of the mutant receptor to bind capsaicin, an alteration of the cation selectivity and permeability properties of the pore, or a disruption of the agonist-induced allosteric conformation that gates the channel. The first possibility would imply that the NML sequence is in the capsaicin binding site or modulates access to it. This is unlikely, because the NML residues and flanking sequences are completely conserved in both VRL-1 and SIC proteins, both of which do not respond to capsaicin (Caterina et al., 1999; Suzuki et al., 1999). Also, the ability of the competitive antagonist capsazepine to inhibit the proton response in the NML676FAP mutant suggests that the binding sites for capsaicin and resiniferatoxin are accessible. Finally, $\left[{ }^{3} \mathrm{H}\right] \mathrm{RTX}$ binding affinity is shifted relative to wild-type VR1 but otherwise remains intact, suggesting that the mutant receptor can bind vanilloids.

Because the NML676FAP mutant both retains partial responses to protons that are manifest as inward current at the resting potential and also undergoes calcium-dependent desensitization similar to that of the wild-type VR1 receptor, it is unlikely that cation selectivity and permeability are dramatically affected by this mutation. It will be of interest, however, to determine whether the $\mathrm{P}_{\mathrm{Ca}} / \mathrm{P}_{\mathrm{Na}}$ ratio of proton responses is altered by this mutation, as might occur if the NML residues contribute to the ionic selectivity sequence. It should be noted that the residues we mutated are highly conserved in the sixth transmembrane domains of TRP protein family members and voltage-gated sodium channels. Interestingly, this conservation correlates with the reported high calcium and sodium permeability of VR1 and raises the intriguing possibility that amino acid residues in the sixth transmembrane domain of VR1 might form part of the pore of the channel. Additional mutations in the putative pore loop region and the sixth transmembrane domain are being generated to further refine and test this idea.

It therefore appears more likely that the NML676FAP mutation affects the agonist-induced conformations involved in gating the channel on capsaicin binding. The partial proton response retained in the NML676FAP mutant suggests that this mutation predominantly affects the capsaicin and resiniferatoxin gating of the VR1 channel. Together with the data from the CP621GL mutant, which exhibits enhanced CAP and RTX responses but no change in proton responses (Fig. 2D), these results lend additional support to the proposal (Tominaga et al., 1998) that the gating mechanisms for the protons and capsaicin are different. The strongest evidence for this dichotomy comes from a recent report of a mutant (E648A) in which proton responses are suppressed but responses to capsaicin are retained, the phenotypic opposite of the NML676FAP mutant (Jordt et al., 2000).

The influence of $\mathrm{pH}$ on VR1 can be characterized in two ways. At room temperature, protons can directly activate VR1 even at moderately acidic levels relative to physiological $\mathrm{pH}$. In addition, acidic solutions that of themselves fail to activate the receptor can sensitize VR1 to activation by capsaicin or heat (Tominaga et al., 1998). The $\mathrm{pH}$ range over which these phenomena occur suggests a titratable group in the physiological range. A recent study in which candidate titratable residues (His, Glu, and Asp) in putative extracellular domains of VR1 were mutated demonstrated that a key glutamine residue $\left(\mathrm{Glu}^{600}\right)$ is involved in proton sensitization of both capsaicin and heat responses (Jordt et al., 2000). In this study, mutation of the nearby histidine (H614Q) yielded a receptor with normal capsaicin and proton responses. We have verified this observation in the H614T mutant that responded robustly to both capsaicin and protons and was thus not a suitable candidate for a dominant negative subunit. However, we additionally observed that the H614T mutation prevented sensitization of the capsaicin response by low $\mathrm{pH}$. In contrast to E600Q which exhibits abnormal direct proton responses (Jordt et al., 2000), mutation of His ${ }^{614}$ alters sensitization of capsaicin responses by protons and not the direct proton activation of the receptor. It thus appears that several amino acids in and around the putative pore domain may regulate VR1 responses to a number of different stimuli in complex manners.

Although additional mutations and analysis are clearly of interest, our present observations suggest that the various functions of VR1 that contribute to its multimodal nociceptive properties may well reside in distinct regions of the molecule. Certainly vanilloid and proton responsiveness are segregated to some extent, and it would not be unexpected that regulation of thermal responses might reside in yet another region of the protein. Finally, the dominant negative nature of the NML676FAP mutation provides a new tool with which to examine the molecular and functional properties of native capsaicin receptors. Using this dominant-negative mutant, we are exploring the function of the VR1 receptor in vivo and assessing whether the VR1 receptor forms heteromultimeric complexes with the recently cloned VRL-1 (Caterina et al., 1999) and SIC (Suzuki et al., 1999) proteins, as well as the TRP family of store-operated calcium channels.

\section{REFERENCES}

Baumann TK, Martenson ME (2000) Extracellular protons both increase the activity and reduce the conductance of capsaicin-gated channels. J Neurosci 20:RC80(1-5).

Caterina MJ, Julius D (2001) The vanilloid receptor: a molecular gateway to the pain pathway. Annu Rev Neurosci 24:487-517.

Caterina MJ, Schumacher MA, Tominaga M, Rosen TA, Levine JD, Julius D (1997) The capsaicin receptor: a heat-activated ion channel in the pain pathway. Nature 389:816-824.

Caterina MJ, Rosen TA, Tominaga M, Brake AJ, Julius D (1999) A capsaicin-receptor homologue with a high threshold for noxious heat. Nature 398:436-441.

Docherty RJ, Yeats JC, Bevan S, Boddeke HW (1996) Inhibition of calcineurin inhibits the desensitization of capsaicin-evoked currents in 
cultured dorsal root ganglion neurons from adult rats. Pflugers Arch 431:828-837.

Guo A, Vulchanova L, Wang J, Li X, Elde R (1999) Immunocytochemical localization of the vanilloid receptor 1 (VR1): relationship to neuropeptides, the $\mathrm{P} 2 \mathrm{X}_{3}$ purinoceptor and IB4 binding sites. Eur J Neurosci 11:946-958.

Jordt S-E, Tominaga M, Julius D (2000) Acid potentiation of the capsaicin receptor determined by a key extracellular site. Proc Natl Acad Sci USA 97:8134-8139.

Kedei N, Szabo T, Lile JD, Treanor JJ, Olah Z, Iadarola MJ, Blumberg PM (2001) Analysis of the native quaternary structure of vanilloid receptor 1. J Biol Chem 276:28613-28619.

Koplas PA, Rosenberg RL, Oxford GS (1997) The role of calcium in the desensitization of capsaicin responses in rat dorsal root ganglion neurons. J Neurosci 17:3525-3537.

Liu L, Simon SA (1996) Capsaicin-induced currents with distinct desensitization and $\mathrm{Ca}^{2+}$ dependence in rat trigeminal ganglion cells. J Neurophysiol 75:1503-1514.

MacKinnon R, Aldrich RW, Lee AW (1993) Functional stoichiometry of Shaker potassium channel inactivation. Science 262:757-759.

Oxford GS, Kuzhikandathil EV, Szabo T, Wang H, Blumberg PM (2000) Use of a dominant negative mutant of VR1 to explore capsaicin receptor stoichiometry. Soc Neurosci Abstr 26:1689.

Sharkey L, Wang H, Kuzhikandathil EV, Oxford GS (1999) Mutations in the putative sixth transmembrane domain provide evidence for multimerization of the VR1 receptor. Soc Neurosci Abstr 25:690.

Suzuki M, Sato J, Kutsuwada K, Ooki G, Imai M (1999) Cloning of a stretch-inhibitable nonselective cation channel. J Biol Chem 274:6330-6335.
Szallasi A, Blumberg PM (1999) Vanilloid (capsaicin) receptors and mechanisms. Pharmacol Rev 51:159-211.

Szallasi A, Lewin NE, Blumberg PM (1992) Identification of alpha-1acid glycoprotein (orosomucoid) as a major vanilloid binding protein in serum. J Pharmacol Exp Ther 262:883-888.

Szallasi A, Blumberg PM, Annicelli LL, Krause JE, Cortright DN (1999) The cloned rat vanilloid receptor VR1 mediates both R-type binding and C-type calcium response in dorsal root ganglion neurons. Mol Pharmacol 56:581-587.

Tinker A, Jan YN, Jan LY (1996) Regions responsible for the assembly of inwardly rectifying potassium channels. Cell 87:857-868.

Tominaga M, Caterina MJ, Malmberg AB, Rosen TA, Gilbert H, Skinner K, Raumann BE, Basbaum AI, Julius D (1998) The cloned capsaicin receptor integrates multiple pain-producing stimuli. Neuron 21:531-543.

Tzounopoulous T, Guy HR, Durell S, Adelman JP, Maylie J (1995) Min K channels form by assembly of at least 14 subunits. Proc Natl Acad Sci USA 92:9593-9597.

Welch JM, Simon SA, Reinhart PH (2000) The activation mechanism of rat vanilloid receptor 1 by capsaicin involves the pore domain and differs from the activation by either acid or heat. Proc Natl Acad Sci USA 97:13889-13894.

Yellen G, Jurman ME, Abramson T, MacKinnon R (1991) Mutations affecting internal TEA blockade identify the probable pore-forming region of a $\mathrm{K}^{+}$channel. Science 251:939-942.

Yool AJ, Schwarz TL (1991) Alteration of ionic selectivity of a $\mathrm{K}^{+}$ channel by mutation of the H5 region. Nature 349:700-704. 